\title{
A New Strong Convergence Theorem for Equilibrium Problems and Fixed Point Problems in Banach Spaces
}

\section{Weerayuth Nilsrakoo}

Department of Mathematics, Statistics and Computer, Faculty of Science, Ubon Ratchathani University, Ubon Ratchathani 34190, Thailand

Correspondence should be addressed to Weerayuth Nilsrakoo, nilsrakoo@hotmail.com

Received 5 June 2010; Revised 28 December 2010; Accepted 20 January 2011

Academic Editor: Fabio Zanolin

Copyright (C) 2011 Weerayuth Nilsrakoo. This is an open access article distributed under the Creative Commons Attribution License, which permits unrestricted use, distribution, and reproduction in any medium, provided the original work is properly cited.

We introduce a new iterative sequence for finding a common element of the set of fixed points of a relatively nonexpansive mapping and the set of solutions of an equilibrium problem in a Banach space. Then, we study the strong convergence of the sequences. With an appropriate setting, we obtain the corresponding results due to Takahashi-Takahashi and Takahashi-Zembayashi. Some of our results are established with weaker assumptions.

\section{Introduction}

Throughout this paper, we denote by $\mathbb{N}$ and $\mathbb{R}$ the sets of positive integers and real numbers, respectively. Let $E$ be a Banach space, $E^{*}$ the dual space of $E$ and $C$ a closed convex subsets of $E$. Let $F: C \times C \rightarrow \mathbb{R}$ be a bifunction. The equilibrium problem is to find $x \in C$ such that

$$
F(x, y) \geq 0, \quad \forall y \in C
$$

The set of solutions of (1.1) is denoted by $\mathrm{EP}(F)$. The equilibrium problems include fixed point problems, optimization problems, variational inequality problems, and Nash equilibrium problems as special cases.

Let $E$ be a smooth Banach space and $J$ the normalized duality mapping from $E$ to $E^{*}$. Alber [1] considered the following functional $\varphi: E \times E \rightarrow[0, \infty)$ defined by

$$
\varphi(x, y)=\|x\|^{2}-2\langle x, J y\rangle+\|y\|^{2} \quad(x, y \in E) .
$$


Using this functional, Matsushita and Takahashi $[2,3]$ studied and investigated the following mappings in Banach spaces. A mapping $S: C \rightarrow E$ is relatively nonexpansive if the following properties are satisfied:

(R1) $F(S) \neq \varnothing$,

(R2) $\varphi(p, S x) \leq \varphi(p, x)$ for all $p \in F(S)$ and $x \in C$,

(R3) $F(S)=\widehat{F}(S)$,

where $F(S)$ and $\widehat{F}(S)$ denote the set of fixed points of $S$ and the set of asymptotic fixed points of $S$, respectively. It is known that $S$ satisfies condition (R3) if and only if $I-S$ is demiclosed at zero, where $I$ is the identity mapping; that is, whenever a sequence $\left\{x_{n}\right\}$ in $C$ converges weakly to $p$ and $\left\{x_{n}-S x_{n}\right\}$ converges strongly to 0 , it follows that $p \in F(S)$. In a Hilbert space $H$, the duality mapping $J$ is an identity mapping and $\varphi(x, y)=\|x-y\|^{2}$ for all $x, y \in H$. Hence, if $S: C \rightarrow H$ is nonexpansive (i.e., $\|S x-S y\| \leq\|x-y\|$ for all $x, y \in C$ ), then it is relatively nonexpansive.

Recently, many authors studied the problems of finding a common element of the set of fixed points for a mapping and the set of solutions of equilibrium problem in the setting of Hilbert space and uniformly smooth and uniformly convex Banach space, respectively (see, e.g., [4-21] and the references therein). In a Hilbert space $H$, S. Takahashi and W. Takahashi [17] introduced the iteration as follows: sequence $\left\{x_{n}\right\}$ generated by $u, x_{1} \in C$,

$$
\begin{gathered}
F\left(z_{n}, y\right)+\frac{1}{r_{n}}\left\langle y-z_{n}, z_{n}-x_{n}\right\rangle \geq 0, \quad \forall y \in C, \\
x_{n+1}=\beta_{n} x_{n}+\left(1-\beta_{n}\right) S\left(\alpha_{n} u+\left(1-\alpha_{n}\right) z_{n}\right),
\end{gathered}
$$

for every $n \in \mathbb{N}$, where $S$ is nonexpansive, $\left\{\alpha_{n}\right\}$ and $\left\{\beta_{n}\right\}$ are appropriate sequences in $[0,1]$, and $\left\{r_{n}\right\}$ is an appropriate positive real sequence. They proved that $\left\{x_{n}\right\}$ converges strongly to some element in $F(S) \cap \operatorname{EP}(F)$. In 2009, Takahashi and Zembayashi [19] proposed the iteration in a uniformly smooth and uniformly convex Banach space as follows: a sequence $\left\{x_{n}\right\}$ generated by $u_{1} \in E$,

$$
\begin{gathered}
x_{n} \in C \text { such that } F\left(x_{n}, y\right)+\frac{1}{r_{n}}\left\langle y-x_{n} J x_{n}-J u_{n}\right\rangle \geq 0, \quad \forall y \in C, \\
u_{n+1}=J^{-1}\left(\alpha_{n} J x_{n}+\left(1-\alpha_{n}\right) J S x_{n}\right),
\end{gathered}
$$

for every $n \in \mathbb{N}, S$ is relatively nonexpansive, $\left\{\alpha_{n}\right\}$ is an appropriate sequence in $[0,1]$, and $\left\{r_{n}\right\}$ is an appropriate positive real sequence. They proved that if $J$ is weakly sequentially continuous, then $\left\{x_{n}\right\}$ converges weakly to some element in $F(S) \cap \operatorname{EP}(F)$.

Motivated by S. Takahashi and W. Takahashi [17] and Takahashi and Zembayashi [19], we prove a strong convergence theorem for finding a common element of the fixed points set of a relatively nonexpansive mapping and the set of solutions of an equilibrium problem in a uniformly smooth and uniformly convex Banach space. 


\section{Preliminaries}

We collect together some definitions and preliminaries which are needed in this paper. We say that a Banach space $E$ is strictly convex if the following implication holds for $x, y \in E$ :

$$
\|x\|=\|y\|=1, \quad x \neq y \text { imply }\left\|\frac{x+y}{2}\right\|<1 .
$$

It is also said to be uniformly convex if for any $\varepsilon>0$, there exists $\delta>0$ such that

$$
\|x\|=\|y\|=1, \quad\|x-y\| \geq \varepsilon \text { imply }\left\|\frac{x+y}{2}\right\| \leq 1-\delta .
$$

It is known that if $E$ is a uniformly convex Banach space, then $E$ is reflexive and strictly convex. We say that $E$ is uniformly smooth if the dual space $E^{*}$ of $E$ is uniformly convex. A Banach space $E$ is smooth if the $\operatorname{limit}_{t \rightarrow 0}((\|x+t y\|-\|x\|) / t)$ exists for all norm one elements $x$ and $y$ in $E$. It is not hard to show that if $E$ is reflexive, then $E$ is smooth if and only if $E^{*}$ is strictly convex.

Let $E$ be a smooth Banach space. The function $\varphi: E \times E \rightarrow \mathbb{R}$ (see [1]) is defined by

$$
\varphi(x, y)=\|x\|^{2}-2\langle x, J y\rangle+\|y\|^{2} \quad(x, y \in E)
$$

where the duality mapping $J: E \rightarrow E^{*}$ is given by

$$
\langle x, J x\rangle=\|x\|^{2}=\|J x\|^{2} \quad(x \in E) .
$$

It is obvious from the definition of the function $\varphi$ that

$$
\begin{gathered}
(\|x\|-\|y\|)^{2} \leq \varphi(x, y) \leq(\|x\|+\|y\|)^{2}, \\
\varphi\left(x, J^{-1}(\lambda J y+(1-\lambda) J z)\right) \leq \lambda \varphi(x, y)+(1-\lambda) \varphi(x, z),
\end{gathered}
$$

for all $\lambda \in[0,1]$ and $x, y, z \in E$. The following lemma is an analogue of Xu's inequality [22, Theorem 2] with respect to $\varphi$.

Lemma 2.1. Let E be a uniformly smooth Banach space and $r>0$. Then, there exists a continuous, strictly increasing, and convex function $g:[0,2 r] \rightarrow[0, \infty)$ such that $g(0)=0$ and

$$
\varphi\left(x, J^{-1}(\lambda J y+(1-\lambda) J z)\right) \leq \lambda \varphi(x, y)+(1-\lambda) \varphi(x, z)-\lambda(1-\lambda) g(\|J y-J z\|)
$$

for all $\lambda \in[0,1], x \in E$, and $y, z \in B_{r}$.

It is also easy to see that if $\left\{x_{n}\right\}$ and $\left\{y_{n}\right\}$ are bounded sequences of a smooth Banach space $E$, then $x_{n}-y_{n} \rightarrow 0$ implies that $\varphi\left(x_{n}, y_{n}\right) \rightarrow 0$. 
Lemma 2.2 (see [23, Proposition 2]). Let E be a uniformly convex and smooth Banach space, and let $\left\{x_{n}\right\}$ and $\left\{y_{n}\right\}$ be two sequences of $E$ such that $\left\{x_{n}\right\}$ or $\left\{y_{n}\right\}$ is bounded. If $\varphi\left(x_{n}, y_{n}\right) \rightarrow 0$, then $x_{n}-y_{n} \rightarrow 0$.

Remark 2.3. For any bounded sequences $\left\{x_{n}\right\}$ and $\left\{y_{n}\right\}$ in a uniformly convex and uniformly smooth Banach space $E$, we have

$$
\varphi\left(x_{n}, y_{n}\right) \longrightarrow 0 \Longleftrightarrow x_{n}-y_{n} \longrightarrow 0 \Longleftrightarrow J x_{n}-J y_{n} \longrightarrow 0
$$

Let $C$ be a nonempty closed convex subset of a reflexive, strictly convex, and smooth Banach space $E$. It is known that $[1,23]$ for any $x \in E$, there exists a unique point $\widehat{x} \in C$ such that

$$
\varphi(\widehat{x}, x)=\min _{y \in C} \varphi(y, x)
$$

Following Alber [1], we denote such an element $\widehat{x}$ by $\Pi_{C} x$. The mapping $\Pi_{C}$ is called the generalized projection from $E$ onto $C$. It is easy to see that in a Hilbert space, the mapping $\Pi_{C}$ coincides with the metric projection $P_{C}$. Concerning the generalized projection, the following are well known.

Lemma 2.4 (see [23, Propositions 4 and 5]). Let $C$ be a nonempty closed convex subset of a reflexive, strictly convex and smooth Banach space $E, x \in E$, and $\hat{x} \in C$. Then,

(a) $\widehat{x}=\Pi_{C} x$ if and only if $\langle y-\widehat{x}, J x-J \widehat{x}\rangle \leq 0$ for all $y \in C$,

(b) $\varphi\left(y, \Pi_{C} x\right)+\varphi\left(\Pi_{C} x, x\right) \leq \varphi(y, x)$ for all $y \in C$.

Remark 2.5. The generalized projection mapping $\Pi_{C}$ above is relatively nonexpansive and $F\left(\Pi_{C}\right)=C$.

Let $E$ be a reflexive, strictly convex and smooth Banach space. The duality mapping $J^{*}$ from $E^{*}$ onto $E^{* *}=E$ coincides with the inverse of the duality mapping $J$ from $E$ onto $E^{*}$, that is, $J^{*}=J^{-1}$. We make use of the following mapping $V: E \times E^{*} \rightarrow \mathbb{R}$ studied in Alber [1]

$$
V\left(x, x^{*}\right)=\|x\|^{2}-2\left\langle x, x^{*}\right\rangle+\left\|x^{*}\right\|^{2},
$$

for all $x \in E$ and $x^{*} \in E^{*}$. Obviously, $V\left(x, x^{*}\right)=\varphi\left(x, J^{-1}\left(x^{*}\right)\right)$ for all $x \in E$ and $x^{*} \in E^{*}$. We know the following lemma (see [1] and [24, Lemma 3.2]).

Lemma 2.6. Let $E$ be a reflexive, strictly convex and smooth Banach space, and let $V$ be as in (2.10). Then,

$$
V\left(x, x^{*}\right)+2\left\langle J^{-1}\left(x^{*}\right)-x, y^{*}\right\rangle \leq V\left(x, x^{*}+y^{*}\right)
$$

for all $x \in E$ and $x^{*}, y^{*} \in E^{*}$. 
Lemma 2.7 (see [25, Lemma 2.1]). Let $\left\{a_{n}\right\}$ be a sequence of nonnegative real numbers. Suppose that

$$
a_{n+1} \leq\left(1-\gamma_{n}\right) a_{n}+\gamma_{n} \delta_{n}
$$

for all $n \in \mathbb{N}$, where the sequences $\left\{\gamma_{n}\right\}$ in $(0,1)$ and $\left\{\delta_{n}\right\}$ in $\mathbb{R}$ satisfy conditions: $\lim _{n \rightarrow \infty} \gamma_{n}=0$, $\sum_{n=1}^{\infty} \gamma_{n}=\infty$, and $\lim \sup _{n \rightarrow \infty} \delta_{n} \leq 0$. Then, $\lim _{n \rightarrow \infty} a_{n}=0$.

Lemma 2.8 (see [26, Lemma 3.1]). Let $\left\{a_{n}\right\}$ be a sequence of real numbers such that there exists a subsequence $\left\{n_{i}\right\}$ of $\{n\}$ such that $a_{n_{i}}<a_{n_{i}+1}$ for all $i \in \mathbb{N}$. Then, there exists a nondecreasing sequence $\left\{m_{k}\right\} \subset \mathbb{N}$ such that $m_{k} \rightarrow \infty$,

$$
a_{m_{k}} \leq a_{m_{k}+1}, \quad a_{k} \leq a_{m_{k}+1}
$$

for all $k \in \mathbb{N}$. In fact, $m_{k}=\max \left\{j \leq k: a_{j}<a_{j+1}\right\}$.

For solving the equilibrium problem, we usually assume that a bifunction $F: C \times C \rightarrow$ $\mathbb{R}$ satisfies the following conditions:

(A1) $F(x, x)=0$ for all $x \in C$,

(A2) $F$ is monotone, that is, $F(x, y)+F(y, x) \leq 0$, for all $x, y \in C$,

(A3) for all $x, y, z \in C, \limsup _{t \rightarrow 0} F(t z+(1-t) x, y) \leq F(x, y)$,

(A4) for all $x \in C, F(x, \cdot)$ is convex and lower semicontinuous.

The following lemma gives a characterization of a solution of an equilibrium problem.

Lemma 2.9 (see [19, Lemma 2.8 ]). Let $C$ be a nonempty closed convex subset of a reflexive, strictly convex, and uniformly smooth Banach space $E$. Let $F: C \times C \rightarrow \mathbb{R}$ be a bifunction satisfying conditions (A1)-(A4). For $r>0$, define a mapping $T_{r}: E \rightarrow C$ so-called the resolvent of $F$ as follows:

$$
T_{r}(x)=\left\{z \in C: F(z, y)+\frac{1}{r}\langle y-z, J z-J x\rangle \geq 0 \forall y \in C\right\}
$$

for all $x \in E$. Then, the following hold:

(i) $T_{r}$ is single-valued,

(ii) $T_{r}$ is a firmly nonexpansive-type mapping [27], that is, for all $x, y \in E$

$$
\left\langle T_{r} x-T_{r} y, J T_{r} x-J T_{r} y\right\rangle \leq\left\langle T_{r} x-T_{r} y, J x-J y\right\rangle,
$$

(iii) $F\left(T_{r}\right)=\mathrm{EP}(F)$,

(iv) $\mathrm{EP}(F)$ is closed and convex,

Lemma 2.10 (see [4, Lemma 2.3]). Let $C$ be a nonempty closed convex subset of a Banach space E, $F$ a bifunction from $C \times C \rightarrow \mathbb{R}$ satisfying conditions (A1)-(A4) and $z \in C$. Then, $z \in \operatorname{EP}(F)$ if and only if $F(y, z) \leq 0$ for all $y \in C$. 
Remark 2.11 (see [27]). Let $C$ be a nonempty subset of a smooth Banach space $E$. If $S: C \rightarrow E$ is a firmly nonexpansive-type mapping, then

$$
\varphi(z, S x) \leq \varphi(z, S x)+\varphi(S x, x) \leq \varphi(z, x)
$$

for all $x \in C$ and $z \in F(S)$. In particular, $S$ satisfies condition (R2).

Lemma 2.12 (see [3, Proposition 2.4]). Let $C$ be a nonempty closed convex subset of a strictly convex and smooth Banach space $E$ and $S: C \rightarrow E$ a relatively nonexpansive mapping. Then, $F(S)$ is closed and convex.

\section{Main Results}

In this section, we prove a strong convergence theorem for finding a common element of the fixed points set of a relatively nonexpansive mapping and the set of solutions of an equilibrium problem in a uniformly convex and uniformly smooth Banach space.

Theorem 3.1. Let $C$ be a nonempty closed convex subset of a uniformly convex and uniformly smooth Banach space $E$ and $F: C \times C \rightarrow \mathbb{R}$ a bifunction satisfying conditions (A1)-(A4) and $S: C \rightarrow E$ a relatively nonexpansive mapping such that $F(S) \cap \operatorname{EP}(F) \neq \varnothing$. Let $\left\{u_{n}\right\}$ and $\left\{x_{n}\right\}$ be sequences generated by $u \in C, u_{1} \in E$ and

$$
\begin{gathered}
F\left(x_{n}, y\right)+\frac{1}{r_{n}}\left\langle y-x_{n} J x_{n}-J u_{n}\right\rangle \geq 0, \quad \forall y \in C, \\
y_{n}=\Pi_{C} J^{-1}\left(\alpha_{n} J u+\left(1-\alpha_{n}\right) J x_{n}\right), \\
u_{n+1}=J^{-1}\left(\beta_{n} J x_{n}+\left(1-\beta_{n}\right) J S y_{n}\right),
\end{gathered}
$$

for all $n \in \mathbb{N}$, where $\left\{\alpha_{n}\right\} \subset(0,1)$ satisfying $\lim _{n \rightarrow \infty} \alpha_{n}=0$ and $\sum_{n=1}^{\infty} \alpha_{n}=\infty,\left\{\beta_{n}\right\} \subset[a, b] \subset(0,1)$, and $\left\{r_{n}\right\} \subset[c, \infty) \subset(0, \infty)$. Then, $\left\{u_{n}\right\}$ and $\left\{x_{n}\right\}$ converge strongly to $\Pi_{F(S) \cap E P(F)} u$.

Proof. Note that $x_{n}$ can be rewritten as $x_{n}=T_{r_{n}} u_{n}$. Since $F(S) \cap \operatorname{EP}(F)$ is nonempty, closed, and convex, we put $\widehat{u}=\Pi_{F(S) \cap E P(F)} u$. Since $\Pi_{C}, T_{r_{n}}$, and $S$ satisfy condition (R2), by (2.6), we get

$$
\begin{aligned}
\varphi\left(\widehat{u}, y_{n}\right) & \leq \varphi\left(\widehat{u}, J^{-1}\left(\alpha_{n} J u+\left(1-\alpha_{n}\right) J x_{n}\right)\right) \\
& \leq \alpha_{n} \varphi(\widehat{u}, u)+\left(1-\alpha_{n}\right) \varphi\left(\widehat{u}, x_{n}\right) \\
& \leq \alpha_{n} \varphi(\widehat{u}, u)+\left(1-\alpha_{n}\right) \varphi\left(\widehat{u}, u_{n}\right),
\end{aligned}
$$


and so

$$
\begin{aligned}
\varphi\left(\widehat{u}, u_{n+1}\right) & \leq \beta_{n} \varphi\left(\widehat{u}, x_{n}\right)+\left(1-\beta_{n}\right) \varphi\left(\widehat{u}, S y_{n}\right) \\
& \leq \beta_{n} \varphi\left(\widehat{u}, u_{n}\right)+\left(1-\beta_{n}\right) \varphi\left(\widehat{u}, y_{n}\right) \\
& \leq \alpha_{n}\left(1-\beta_{n}\right) \varphi(\widehat{u}, u)+\left(1-\alpha_{n}\left(1-\beta_{n}\right)\right) \varphi\left(\widehat{u}, u_{n}\right) \\
& \leq \max \left\{\varphi(\widehat{u}, u), \varphi\left(\widehat{u}, u_{n}\right)\right\} .
\end{aligned}
$$

By induction, we have

$$
\varphi\left(z, u_{n+1}\right) \leq \max \left\{\varphi(\widehat{u}, u), \varphi\left(\widehat{u}, u_{1}\right)\right\},
$$

for all $n \in \mathbb{N}$. This implies that $\left\{u_{n}\right\}$ is bounded and so are $\left\{x_{n}\right\},\left\{y_{n}\right\}$, and $\left\{S y_{n}\right\}$. Put

$$
z_{n} \equiv J^{-1}\left(\alpha_{n} J u+\left(1-\alpha_{n}\right) J x_{n}\right) .
$$

Then, $y_{n} \equiv \Pi_{C} z_{n}$. Using Lemma 2.6 gives

$$
\begin{aligned}
\varphi\left(\widehat{u}, y_{n}\right) & \leq \varphi\left(\widehat{u}, z_{n}\right)=V\left(\widehat{u}, J z_{n}\right) \\
& \leq V\left(\widehat{u}, J z_{n}-\alpha_{n}(J u-J \widehat{u})\right)-2\left\langle z_{n}-\widehat{u},-\alpha_{n}(J u-J \widehat{u})\right\rangle \\
& =\varphi\left(\widehat{u}, J^{-1}\left(\alpha_{n} J \widehat{u}+\left(1-\alpha_{n}\right) J x_{n}\right)\right)+2 \alpha_{n}\left\langle z_{n}-\widehat{u}, J u-J \widehat{u}\right\rangle \\
& \leq \alpha_{n} \varphi(\widehat{u}, \widehat{u})+\left(1-\alpha_{n}\right) \varphi\left(\widehat{u}, x_{n}\right)+2 \alpha_{n}\left\langle z_{n}-\widehat{u}, J u-J \widehat{u}\right\rangle \\
& \leq\left(1-\alpha_{n}\right) \varphi\left(\widehat{u}, u_{n}\right)+2 \alpha_{n}\left\langle z_{n}-\widehat{u}, J u-J \widehat{u}\right\rangle .
\end{aligned}
$$

Let $g:[0,2 r] \rightarrow[0, \infty)$ be a function satisfying the properties of Lemma 2.1, where $r=$ $\sup \left\{\left\|x_{n}\right\|,\left\|S y_{n}\right\|: n \in \mathbb{N}\right\}$. Then, by Remark 2.11 and (3.6), we get

$$
\begin{aligned}
\varphi\left(\widehat{u}, u_{n+1}\right) \leq & \beta_{n} \varphi\left(\widehat{u}, x_{n}\right)+\left(1-\beta_{n}\right) \varphi\left(\widehat{u}, S y_{n}\right)-\beta_{n}\left(1-\beta_{n}\right) g\left(\left\|J x_{n}-J S y_{n}\right\|\right) \\
\leq & \beta_{n}\left(\varphi\left(\widehat{u}, u_{n}\right)-\varphi\left(x_{n}, u_{n}\right)\right)+\left(1-\beta_{n}\right) \varphi\left(\widehat{u}, y_{n}\right) \\
& -\beta_{n}\left(1-\beta_{n}\right) g\left(\left\|J x_{n}-J S y_{n}\right\|\right) \\
\leq & \beta_{n} \varphi\left(\widehat{u}, u_{n}\right)+\left(1-\beta_{n}\right)\left(\left(1-\alpha_{n}\right) \varphi\left(\widehat{u}, u_{n}\right)+2 \alpha_{n}\left\langle z_{n}-\widehat{u}, J u-J \widehat{u}\right\rangle\right) \\
& -\beta_{n} \varphi\left(x_{n}, u_{n}\right)-\beta_{n}\left(1-\beta_{n}\right) g\left(\left\|J x_{n}-J S y_{n}\right\|\right) \\
= & \left(1-\gamma_{n}\right) \varphi\left(\widehat{u}, u_{n}\right)+2 \gamma_{n}\left\langle z_{n}-\widehat{u}, J u-J \widehat{u}\right\rangle \\
& -\beta_{n} \varphi\left(x_{n}, u_{n}\right)-\beta_{n}\left(1-\beta_{n}\right) g\left(\left\|J x_{n}-J S y_{n}\right\|\right) \\
\leq & \left(1-\gamma_{n}\right) \varphi\left(\widehat{u}, u_{n}\right)+2 \gamma_{n}\left\langle z_{n}-\widehat{u}, J u-J \widehat{u}\right\rangle,
\end{aligned}
$$

where $\gamma_{n}=\alpha_{n}\left(1-\beta_{n}\right)$ for all $n \in \mathbb{N}$. Notice that $\left\{\gamma_{n}\right\} \subset(0,1)$ satisfying $\lim _{n \rightarrow \infty} \gamma_{n}=0$ and $\sum_{n=1}^{\infty} \gamma_{n}=\infty$. 
The rest of the proof will be divided into two parts.

Case 1. Suppose that there exists $n_{0} \in \mathbb{N}$ such that $\left\{\varphi\left(\widehat{u}, u_{n}\right)\right\}_{n=n_{0}}^{\infty}$ is nonincreasing. In this situation, $\left\{\varphi\left(\widehat{u}, u_{n}\right)\right\}$ is then convergent. Then,

$$
\varphi\left(\widehat{u}, u_{n}\right)-\varphi\left(\widehat{u}, u_{n+1}\right) \longrightarrow 0
$$

It follows from (3.7) and $\gamma_{n} \rightarrow 0$ that

$$
\beta_{n} \varphi\left(x_{n}, u_{n}\right)+\beta_{n}\left(1-\beta_{n}\right) g\left(\left\|J x_{n}-J S y_{n}\right\|\right) \longrightarrow 0
$$

Since $\left\{\beta_{n}\right\} \subset[a, b] \subset(0,1)$,

$$
\varphi\left(x_{n}, u_{n}\right) \longrightarrow 0, \quad g\left(\left\|J x_{n}-J S y_{n}\right\|\right) \longrightarrow 0
$$

Consequently, by Remark 2.3,

$$
x_{n}-u_{n} \longrightarrow 0, \quad J x_{n}-J S y_{n} \longrightarrow 0, \quad x_{n}-S y_{n} \longrightarrow 0 .
$$

From (2.6) and $\alpha_{n} \rightarrow 0$, we obtain

$$
\varphi\left(x_{n}, y_{n}\right) \leq \varphi\left(x_{n}, z_{n}\right) \leq \alpha_{n} \varphi\left(x_{n}, u\right)+\left(1-\alpha_{n}\right) \varphi\left(x_{n}, x_{n}\right)=\alpha_{n} \varphi\left(x_{n}, u\right) \longrightarrow 0
$$

This implies that

$$
x_{n}-y_{n} \longrightarrow 0, \quad z_{n}-y_{n} \longrightarrow 0
$$

Therefore,

$$
y_{n}-S y_{n} \longrightarrow 0
$$

Since $\left\{y_{n}\right\}$ is bounded and $E$ is reflexive, we choose a subsequence $\left\{y_{n_{i}}\right\}$ of $\left\{y_{n}\right\}$ such that $y_{n_{i}} \rightarrow z$ and

$$
\limsup _{n \rightarrow \infty}\left\langle y_{n}-\widehat{u}, J u-J \widehat{u}\right\rangle=\lim _{i \rightarrow \infty}\left\langle y_{n_{i}}-\widehat{u}, J u-J \widehat{u}\right\rangle .
$$

Then, $x_{n_{i}}-z$. Since $x_{n}-u_{n} \rightarrow 0$ and $r_{n} \geq c>0$, by Remark 2.3,

$$
\lim _{n \rightarrow \infty} \frac{1}{r_{n}}\left\|J x_{n}-J u_{n}\right\|=0 .
$$

Notice that

$$
F\left(x_{n}, y\right)+\frac{1}{r_{n}}\left\langle y-x_{n}, J x_{n}-J u_{n}\right\rangle \geq 0, \quad \forall y \in C .
$$


Fixed Point Theory and Applications

Replacing $n$ by $n_{i}$, we have from (A2) that

$$
\frac{1}{r_{n_{i}}}\left\langle y-x_{n_{i}}, J x_{n_{i}}-J u_{n_{i}}\right\rangle \geq-F\left(x_{n_{i}}, y\right) \geq F\left(y, x_{n_{i}}\right), \quad \forall y \in C
$$

Letting $i \rightarrow \infty$, we have from (3.17) and (A4) that

$$
F(y, z) \leq 0, \quad \forall y \in C
$$

From Lemma 2.10, we have $z \in \mathrm{EP}(F)$. Since $S$ satisfies condition (R3) and (3.15), $z \in F(S)$. It follows that $z \in F(S) \cap \mathrm{EP}(F)$. By Lemma 2.4(a), we immediately obtain that

$$
\limsup _{n \rightarrow \infty}\left\langle y_{n}-\widehat{u}, J u-J \widehat{u}\right\rangle=\langle z-\widehat{u}, J u-J \widehat{u}\rangle \leq 0
$$

Since $z_{n}-y_{n} \rightarrow 0$,

$$
\limsup _{n \rightarrow \infty}\left\langle z_{n}-\widehat{u}, J u-J \widehat{u}\right\rangle \leq 0
$$

It follows from Lemma 2.7 and (3.8) that $\varphi\left(\widehat{u}, u_{n}\right) \rightarrow 0$. Then, $u_{n} \rightarrow \widehat{u}$ and so $x_{n} \rightarrow \widehat{u}$.

Case 2. Suppose that there exists a subsequence $\left\{n_{i}\right\}$ of $\{n\}$ such that

$$
\varphi\left(\widehat{u}, u_{n_{i}}\right)<\varphi\left(\widehat{u}, u_{n_{i}+1}\right)
$$

for all $i \in \mathbb{N}$. Then, by Lemma 2.8, there exists a nondecreasing sequence $\left\{m_{k}\right\} \subset \mathbb{N}$ such that $m_{k} \rightarrow \infty$,

$$
\varphi\left(\widehat{u}, u_{m_{k}}\right) \leq \varphi\left(\widehat{u}, u_{m_{k}+1}\right), \quad \varphi\left(\widehat{u}, u_{k}\right) \leq \varphi\left(\widehat{u}, u_{m_{k}+1}\right)
$$

for all $k \in \mathbb{N}$. From (3.7) and $\gamma_{n} \rightarrow 0$, we have

$$
\begin{aligned}
& \beta_{m_{k}} \varphi\left(x_{m_{k}}, u_{m_{k}}\right)+\beta_{m_{k}}\left(1-\beta_{m_{k}}\right) g\left(\left\|J x_{m_{k}}-J S y_{m_{k}}\right\|\right) \\
& \quad \leq\left(\varphi\left(\widehat{u}, u_{m_{k}}\right)-\varphi\left(\widehat{u}, u_{m_{k}+1}\right)\right)-\gamma_{m_{k}} \varphi\left(\widehat{u}, u_{m_{k}}\right)+2 \gamma_{m_{k}}\left\langle z_{m_{k}}-\widehat{u}, J u-J \widehat{u}\right\rangle \\
& \quad \leq-\gamma_{m_{k}} \varphi\left(\widehat{u}, u_{m_{k}}\right)+2 \gamma_{m_{k}}\left\langle z_{m_{k}}-\widehat{u}, J u-J \widehat{u}\right\rangle \longrightarrow 0 .
\end{aligned}
$$

Using the same proof of Case 1, we also obtain

$$
\limsup _{k \rightarrow \infty}\left\langle z_{m_{k}}-\widehat{u}, J u-J \widehat{u}\right\rangle \leq 0 .
$$

From (3.8), we have

$$
\varphi\left(\widehat{u}, u_{m_{k}+1}\right) \leq\left(1-\gamma_{m_{k}}\right) \varphi\left(\widehat{u}, u_{m_{k}}\right)+2 \gamma_{m_{k}}\left\langle z_{m_{k}}-\widehat{u}, J u-J \widehat{u}\right\rangle .
$$


Since $\varphi\left(\widehat{u}, u_{m_{k}}\right) \leq \varphi\left(\widehat{u}, u_{m_{k}+1}\right)$, we have

$$
\begin{aligned}
\gamma_{m_{k}} \varphi\left(\widehat{u}, u_{m_{k}}\right) & \leq \varphi\left(\widehat{u}, u_{m_{k}}\right)-\varphi\left(\widehat{u}, u_{m_{k}+1}\right)+2 \gamma_{m_{k}}\left\langle z_{m_{k}}-\widehat{u}, J u-J \widehat{u}\right\rangle \\
& \leq 2 \gamma_{m_{k}}\left\langle y_{m_{k}}-\widehat{u}, J u-J \widehat{u}\right\rangle .
\end{aligned}
$$

In particular, since $\gamma_{m_{k}}>0$, we get

$$
\varphi\left(\widehat{u}, u_{m_{k}}\right) \leq 2\left\langle z_{m_{k}}-\widehat{u}, J u-J \widehat{u}\right\rangle .
$$

It follows from (3.26) that $\varphi\left(\widehat{u}, u_{m_{k}}\right) \rightarrow 0$. This together with (3.27) gives

$$
\varphi\left(\widehat{u}, u_{m_{k}+1}\right) \longrightarrow 0
$$

But $\varphi\left(\widehat{u}, u_{k}\right) \leq \varphi\left(\widehat{u}, u_{m_{k}+1}\right)$ for all $k \in \mathbb{N}$, we conclude that $u_{k} \rightarrow \widehat{u}$, and $x_{k} \rightarrow \widehat{u}$.

From two cases, we can conclude that $\left\{u_{n}\right\}$ and $\left\{x_{n}\right\}$ converge strongly to $\widehat{u}$ and the proof is finished.

Applying Theorem 3.1 and [28, Theorem 3.2], we have the following result.

Theorem 3.2. Let $C$ be a nonempty closed convex subset of a uniformly convex and uniformly smooth Banach space $E, F: C \times C \rightarrow \mathbb{R}$ a bifunction satisfying conditions (A1)-(A4), and $\left\{T_{i}: C \rightarrow E\right\}_{i=1}^{\infty}$ a sequence of relatively nonexpansive mappings such that $\bigcap_{i=1}^{\infty} F\left(T_{i}\right) \cap \operatorname{EP}(F) \neq \varnothing$. Let $\left\{u_{n}\right\}$ and $\left\{x_{n}\right\}$ be sequences generated by (3.1), where $S: C \rightarrow E$ is defined by

$$
S x=J^{-1}\left(\sum_{i=1}^{\infty} \alpha_{i} J T_{i} x\right) \quad \text { for each } x \in C .
$$

Then, $\left\{u_{n}\right\}$ and $\left\{x_{n}\right\}$ converge strongly to $\prod_{\bigcap_{i=1}^{\infty} F\left(T_{i}\right) \cap \mathrm{EP}(F)} u$.

Setting $F \equiv 0$ and $r_{n} \equiv 1$ in Theorem 3.1, we have the following result.

Corollary 3.3. Let $C$ be a nonempty closed convex subset of a uniformly convex and uniformly smooth Banach space $E$ and $S: C \rightarrow E$ a relatively nonexpansive mapping. Let $\left\{u_{n}\right\}$ and $\left\{x_{n}\right\}$ be sequences generated by $u \in C, u_{1} \in E$ and

$$
\begin{gathered}
x_{n}=\Pi_{C} u_{n}, \\
y_{n}=\Pi_{C} J^{-1}\left(\alpha_{n} J u+\left(1-\alpha_{n}\right) J x_{n}\right), \\
u_{n+1}=J^{-1}\left(\beta_{n} J x_{n}+\left(1-\beta_{n}\right) J S y_{n}\right),
\end{gathered}
$$

for all $n \in \mathbb{N}$, where $\left\{\alpha_{n}\right\} \subset(0,1)$ satisfying $\lim _{n \rightarrow \infty} \alpha_{n}=0$ and $\sum_{n=1}^{\infty} \alpha_{n}=\infty,\left\{\beta_{n}\right\} \subset[a, b] \subset(0,1)$. Then, $\left\{u_{n}\right\}$ and $\left\{x_{n}\right\}$ converge strongly to $\Pi_{F(S)} u$. 
Fixed Point Theory and Applications

Letting $S: C \rightarrow C$ in Corollary 3.3, we have the following result.

Corollary 3.4. Let $C$ be a nonempty closed convex subset of a uniformly convex and uniformly smooth Banach space $E$ and $S: C \rightarrow C$ a relatively nonexpansive mapping. Let $\left\{x_{n}\right\}$ be a sequence in $C$ defined by $u \in C, x_{1} \in C$ and

$$
\begin{gathered}
y_{n}=\Pi_{C} J^{-1}\left(\alpha_{n} J u+\left(1-\alpha_{n}\right) J x_{n}\right), \\
x_{n+1}=J^{-1}\left(\beta_{n} J x_{n}+\left(1-\beta_{n}\right) J S y_{n}\right),
\end{gathered}
$$

for all $n \in \mathbb{N}$, where $\left\{\alpha_{n}\right\} \subset(0,1)$ satisfying $\lim _{n \rightarrow \infty} \alpha_{n}=0$ and $\sum_{n=1}^{\infty} \alpha_{n}=\infty,\left\{\beta_{n}\right\} \subset[a, b] \subset(0,1)$. Then $\left\{x_{n}\right\}$ converges strongly to $\Pi_{F(S)} u$.

Let $S$ be the identity mapping in Theorem 3.1, we also have the following result.

Corollary 3.5. Let $C$ be a nonempty closed convex subset of a uniformly convex and uniformly smooth Banach space $E$ and $F: C \times C \rightarrow \mathbb{R}$ a bifunction satisfying conditions (A1)-(A4) such that $\mathrm{EP}(F) \neq \varnothing$. Let $\left\{u_{n}\right\}$ and $\left\{x_{n}\right\}$ be sequences generated by $u \in C, u_{1} \in E$ and

$$
\begin{gathered}
F\left(x_{n}, y\right)+\frac{1}{r_{n}}\left\langle y-x_{n}, J x_{n}-J u_{n}\right\rangle \geq 0, \quad \forall y \in C, \\
y_{n}=\Pi_{C} J^{-1}\left(\alpha_{n} J u+\left(1-\alpha_{n}\right) J x_{n}\right), \\
u_{n+1}=J^{-1}\left(\beta_{n} J x_{n}+\left(1-\beta_{n}\right) J y_{n}\right),
\end{gathered}
$$

for all $n \in \mathbb{N}$, where $\left\{\alpha_{n}\right\} \subset(0,1)$ satisfying $\lim _{n \rightarrow \infty} \alpha_{n}=0$ and $\sum_{n=1}^{\infty} \alpha_{n}=\infty,\left\{\beta_{n}\right\} \subset[a, b] \subset(0,1)$, and $\left\{r_{n}\right\} \subset[c, \infty) \subset(0, \infty)$. Then, $\left\{u_{n}\right\}$ and $\left\{x_{n}\right\}$ converge strongly to $\Pi_{\mathrm{EP}(F)} u$.

\section{Deduced Theorems in Hilbert Spaces}

In Hilbert spaces, every nonexpansive mappings are relatively nonexpansive, and $J$ is the identity operator. We obtain the following result.

Theorem 4.1. Let $C$ be a nonempty closed convex subset of a Hilbert space $H, F: C \times C \rightarrow \mathbb{R}$ a bifunction satisfying conditions (A1)-(A4), and $S: C \rightarrow H$ a nonexpansive mapping such that $F(S) \cap \operatorname{EP}(F) \neq \varnothing$. Let $\left\{x_{n}\right\}$ be a sequence in $C$ defined by $u \in C, x_{1} \in H$ and

$$
x_{n+1}=\beta_{n} T_{r_{n}} x_{n}+\left(1-\beta_{n}\right) S\left(\alpha_{n} u+\left(1-\alpha_{n}\right) T_{r_{n}} x_{n}\right),
$$

for all $n \in \mathbb{N}$, where $T_{r_{n}}$ is the resolvent of $F,\left\{\alpha_{n}\right\} \subset(0,1)$ satisfying $\lim _{n \rightarrow \infty} \alpha_{n}=0$ and $\sum_{n=1}^{\infty} \alpha_{n}=\infty,\left\{\beta_{n}\right\} \subset[a, b] \subset(0,1)$, and $\left\{r_{n}\right\} \subset[c, \infty) \subset(0, \infty)$. Then, $\left\{x_{n}\right\}$ converges strongly to $P_{F(S) \cap E P(F)} u$.

Remark 4.2. In Theorem 4.1, we have the same conclusion if the mapping $S: C \rightarrow H$ is only quasinonexpansive (i.e., $F(S) \neq \varnothing$ and $\|p-S x\| \leq\|p-x\|$ for all $x \in C$ and $p \in F(S)$ ) such that $I-T$ is demiclosed at zero. 
Letting $F \equiv 0$ in Theorem 4.1, we have the following result.

Corollary 4.3. Let $C$ be a nonempty closed convex subset of a Hilbert space $H$ and $S: C \rightarrow H$ a nonexpansive mapping such that $F(S) \neq \varnothing$. Let $\left\{x_{n}\right\}$ be a sequence in $C$ defined by $u \in C, x_{1} \in H$ and

$$
x_{n+1}=\beta_{n} P_{C} x_{n}+\left(1-\beta_{n}\right) S\left(\alpha_{n} u+\left(1-\alpha_{n}\right) P_{C} x_{n}\right),
$$

for all $n \in \mathbb{N}$, where $\left\{\alpha_{n}\right\} \subset(0,1)$ satisfying $\lim _{n \rightarrow \infty} \alpha_{n}=0, \sum_{n=1}^{\infty} \alpha_{n}=\infty$, and $\left\{\beta_{n}\right\} \subset[a, b] \subset$ $(0,1)$. Then, $\left\{x_{n}\right\}$ converges strongly to $P_{F(S)} u$.

Let $S$ be the identity mapping in Theorem 4.1, we have the following result.

Corollary 4.4. Let $C$ be a nonempty closed convex subset of a Hilbert space $H$ and $F: C \times C \rightarrow \mathbb{R} a$ bifunction satisfying conditions (A1)-(A4). Let $\left\{x_{n}\right\}$ be a sequence in $H$ defined by $u, x_{1} \in H$ and

$$
x_{n+1}=\gamma_{n} u+\left(1-\gamma_{n}\right) T_{r_{n}} x_{n},
$$

for all $n \in \mathbb{N}$, where $T_{r_{n}}$ is the resolvent of $F,\left\{\gamma_{n}\right\} \subset(0,1)$ satisfying $\lim _{n \rightarrow \infty} \gamma_{n}=0, \sum_{n=1}^{\infty} \gamma_{n}=\infty$, and $\left\{r_{n}\right\} \subset[c, \infty) \subset(0, \infty)$. Then $\left\{x_{n}\right\}$ converges strongly to $\Pi_{\mathrm{EP}(F)} u$.

Proof. We may assume without loss of generality that $\gamma_{n}<1 / 2$ for all $n \in \mathbb{N}$. Setting $\alpha_{n}=2 \gamma_{n}$ and $\beta_{n}=1 / 2$ for all $n \in \mathbb{N}$, we get

$$
x_{n+1}=\frac{1}{2} T_{r_{n}} x_{n}+\frac{1}{2} I\left(\alpha_{n} u+\left(1-\alpha_{n}\right) T_{r_{n}} x_{n}\right),
$$

$\lim _{n \rightarrow \infty} \alpha_{n}=0$, and $\sum_{n=1}^{\infty} \alpha_{n}=\infty$. Applying Theorem 4.1, $\left\{x_{n}\right\}$ converges strongly to $P_{\operatorname{EP}(F)} u$.

Remark 4.5. Corollary 4.4 improves and extends [29, Corollary 5.3]. More precisely, the conditions $\lim _{n \rightarrow \infty}\left(\gamma_{n+1} / \gamma_{n}\right)=1$ and $\sum_{n=1}^{\infty}\left|r_{n+1}-r_{n}\right|<\infty$ are removed.

Applying Corollary 4.4 and [30, Theorem 8], we have the following result.

Corollary 4.6. Let $C$ be a nonempty closed convex subset of a Hilbert space $H, F: C \times C \rightarrow \mathbb{R} a$ bifunction satisfying conditions (A1)-(A4), and $f: C \rightarrow C$ a contraction of $H$ into itself. Let $\left\{x_{n}\right\}$ be a sequence in $H$ defined by $u, x_{1} \in H$ and

$$
x_{n+1}=\gamma_{n} f\left(x_{n}\right)+\left(1-\gamma_{n}\right) T_{r_{n}} x_{n}
$$

for all $n \in \mathbb{N}$, where $T_{r_{n}}$ is the resolvent of $F,\left\{\gamma_{n}\right\} \subset(0,1)$ satisfying $\lim _{n \rightarrow \infty} \gamma_{n}=0$ and $\sum_{n=1}^{\infty} \gamma_{n}=\infty$ and $\left\{r_{n}\right\} \subset[c, \infty) \subset(0, \infty)$. Then, $\left\{x_{n}\right\}$ converges strongly to $z=P_{\mathrm{EP}(F)} f(z)$.

Remark 4.7. Corollary 4.6 improves and extends [16, Corollary 3.4]. More precisely, the conditions $\sum_{n=1}^{\infty}\left|\gamma_{n+1}-\gamma_{n}\right|<\infty$ and $\sum_{n=1}^{\infty}\left|r_{n+1}-r_{n}\right|<\infty$ are removed. 


\section{Acknowledgment}

The author would like to thank the referees for their comments and helpful suggestions.

\section{References}

[1] Y. I. Alber, "Metric and generalized projection operators in Banach spaces: properties and applications," in Theory and Applications of Nonlinear Operators of Accretive and Monotone Type, vol. 178 of Lecture Notes in Pure and Applied Mathematics, pp. 15-50, Marcel Dekker, New York, NY, USA, 1996.

[2] S.-Y. Matsushita and W. Takahashi, "Weak and strong convergence theorems for relatively nonexpansive mappings in Banach spaces," Fixed Point Theory and Applications, no. 1, pp. 37-47, 2004.

[3] S.-Y. Matsushita and W. Takahashi, "A strong convergence theorem for relatively nonexpansive mappings in a Banach space," Journal of Approximation Theory, vol. 134, no. 2, pp. 257-266, 2005.

[4] D. Boonchari and S. Saejung, "Approximation of common fixed points of a countable family of relatively nonexpansive mappings," Fixed Point Theory and Applications, vol. 2010, Article ID 407651, 26 pages, 2010.

[5] L.-C. Ceng and J.-C. Yao, "A hybrid iterative scheme for mixed equilibrium problems and fixed point problems," Journal of Computational and Applied Mathematics, vol. 214, no. 1, pp. 186-201, 2008.

[6] L. C. Ceng, A. Petruşel, and J. C. Yao, "Iterative approaches to solving equilibrium problems and fixed point problems of infinitely many nonexpansive mappings," Journal of Optimization Theory and Applications, vol. 143, no. 1, pp. 37-58, 2009.

[7] A. Kangtunyakarn and S. Suantai, "A new mapping for finding common solutions of equilibrium problems and fixed point problems of finite family of nonexpansive mappings," Nonlinear Analysis. Theory, Methods E Applications, vol. 71, no. 10, pp. 4448-4460, 2009.

[8] W. Nilsrakoo and S. Saejung, "Weak and strong convergence theorems for countable Lipschitzian mappings and its applications," Nonlinear Analysis. Theory, Methods E Applications, vol. 69, no. 8, pp. 2695-2708, 2008.

[9] W. Nilsrakoo and S. Saejung, "Weak convergence theorems for a countable family of Lipschitzian mappings," Journal of Computational and Applied Mathematics, vol. 230, no. 2, pp. 451-462, 2009.

[10] W. Nilsrakoo and S. Saejung, "Strong convergence theorems for a countable family of quasiLipschitzian mappings and its applications," Journal of Mathematical Analysis and Applications, vol. 356, no. 1, pp. 154-167, 2009.

[11] W. Nilsrakoo and S. Saejung, "Equilibrium problems and Moudafi's viscosity approximation methods in Hilbert spaces," Dynamics of Continuous, Discrete $\mathcal{E}$ Impulsive Systems. Series A. Mathematical Analysis, vol. 17, no. 2, pp. 195-213, 2010.

[12] S. Plubtieng and W. Sriprad, "Hybrid methods for equilibrium problems and fixed points problems of a countable family of relatively nonexpansive mappings in Banach spaces," Fixed Point Theory and Applications, vol. 2010, Article ID 962628, 17 pages, 2010.

[13] S. Plubtieng and W. Sriprad, "A viscosity approximation method for finding common solutions of variational inclusions, equilibrium problems, and fixed point problems in Hilbert spaces," Fixed Point Theory and Applications, vol. 2009, Article ID 567147, 20 pages, 2009.

[14] X. Qin, Y. J. Cho, and S. M. Kang, "Convergence theorems of common elements for equilibrium problems and fixed point problems in Banach spaces," Journal of Computational and Applied Mathematics, vol. 225, no. 1, pp. 20-30, 2009.

[15] A. Tada and W. Takahashi, "Weak and strong convergence theorems for a nonexpansive mapping and an equilibrium problem," Journal of Optimization Theory and Applications, vol. 133, no. 3, pp. 359-370, 2007.

[16] S. Takahashi and W. Takahashi, "Viscosity approximation methods for equilibrium problems and fixed point problems in Hilbert spaces," Journal of Mathematical Analysis and Applications, vol. 331, no. 1, pp. 506-515, 2007.

[17] S. Takahashi and W. Takahashi, "Strong convergence theorem for a generalized equilibrium problem and a nonexpansive mapping in a Hilbert space," Nonlinear Analysis. Theory, Methods E Applications, vol. 69, no. 3, pp. 1025-1033, 2008.

[18] W. Takahashi and K. Zembayashi, "Strong convergence theorem by a new hybrid method for equilibrium problems and relatively nonexpansive mappings," Fixed Point Theory and Applications, vol. 2008, Article ID 528476, 11 pages, 2008. 
[19] W. Takahashi and Kei Zembayashi, "Strong and weak convergence theorems for equilibrium problems and relatively nonexpansive mappings in Banach spaces," Nonlinear Analysis. Theory, Methods E Applications, vol. 70, no. 1, pp. 45-57, 2009.

[20] K. Wattanawitoon and P. Kumam, "Strong convergence theorems by a new hybrid projection algorithm for fixed point problems and equilibrium problems of two relatively quasi-nonexpansive mappings," Nonlinear Analysis. Hybrid Systems, vol. 3, no. 1, pp. 11-20, 2009.

[21] Y. Yao, Y.-C. Liou, and J.-C. Yao, "Convergence theorem for equilibrium problems and fixed point problems of infinite family of nonexpansive mappings," Fixed Point Theory and Applications, vol. 2007, Article ID 64363, 12 pages, 2007.

[22] H. K. Xu, "Inequalities in Banach spaces with applications," Nonlinear Analysis. Theory, Methods $\mathcal{E}$ Applications, vol. 16, no. 12, pp. 1127-1138, 1991.

[23] S. Kamimura and W. Takahashi, "Strong convergence of a proximal-type algorithm in a Banach space," SIAM Journal on Optimization, vol. 13, no. 3, pp. 938-945, 2002.

[24] F. Kohsaka and W. Takahashi, "Strong convergence of an iterative sequence for maximal monotone operators in a Banach space," Abstract and Applied Analysis, no. 3, pp. 239-249, 2004.

[25] H.-K. Xu, "Another control condition in an iterative method for nonexpansive mappings," Bulletin of the Australian Mathematical Society, vol. 65, no. 1, pp. 109-113, 2002.

[26] P.-E. Maingé, "Strong convergence of projected subgradient methods for nonsmooth and nonstrictly convex minimization," Set-Valued Analysis, vol. 16, no. 7-8, pp. 899-912, 2008.

[27] F. Kohsaka and W. Takahashi, "Existence and approximation of fixed points of firmly nonexpansivetype mappings in Banach spaces," SIAM Journal on Optimization, vol. 19, no. 2, pp. 824-835, 2008.

[28] W. Nilsrakoo and S. Saejung, "On the fixed-point set of a family of relatively nonexpansive and generalized nonexpansive mappings," Fixed Point Theory and Applications, vol. 2010, Article ID 414232, 14 pages, 2010.

[29] Y. Song and Y. Zheng, "Strong convergence of iteration algorithms for a countable family of nonexpansive mappings," Nonlinear Analysis. Theory, Methods E Applications, vol. 71, no. 7-8, pp. 30723082, 2009.

[30] T. Suzuki, "Moudafi's viscosity approximations with Meir-Keeler contractions," Journal of Mathematical Analysis and Applications, vol. 325, no. 1, pp. 342-352, 2007. 